\title{
MICROSTRIP PATCH ANTENNA FOR FIFTH GENERATION WIRELESS COMMUNICATION USING DGS TECHNIQUE
}

\author{
M.Ranga Rao \\ Professor \\ Department Of Electronics And Communication Engineering, Vijayawada \\ Potti Sriramulu Chalavadi Mallikarjuna Rao College Of Engineering \& Technology, \\ Vijayawada \\ K. Sowmya, T. Ayyappa, P. Phani Sree \\ Students \\ Department Of Electronics And Communication Engineering, Vijayawada \\ Potti Sriramulu Chalavadi Mallikarjuna Rao College Of Engineering \& Technology, \\ Vijayawada
}

\begin{abstract}
The proposed antenna is presented for the $5 \mathrm{G}$ wireless communication by using DGS technique. In a communication the bandwidth is one of the major parameter to transmit the signals. The $5 \mathrm{G}$ prefers high band width, compactness of size and good return loss. To increase the bandwidth we have various techniques such as multiple slotting technique, meta material, corner cut and DGS technique. The pros of DGS technique is to reduce a micro strip patch antenna resonating at $4.6 \mathrm{GHz}$. For this purpose, DGS is employed to shift the frequency of an initial micro strip antenna from $5.5 \mathrm{GHz}$ to $4.6 \mathrm{GHz}$ without disturbing the current distribution. Comparison of the proposed DGS antenna with other techniques shows the unique capability of the DGS technique to get a beneficial result. The prototype of an antenna was designed with the FR4 substrate 4.4 , thickness $1.6 \mathrm{~mm}$, and the dimensions of the antenna is $33 \times 36 \mathrm{~mm}^{2}$. The proposed antenna is designed for different applications such as INSAT, WLAN and telecommunication.
\end{abstract}

Keywords: Defected ground structure (DGS), micro strip patch antenna.

\section{INTRODUCTION}

The incredible growth of wireless devices has brought various improvements in the fourth advanced standards for communication networks. 4G LTE network have many commercial services it works very efficiently to meet the demands of high- throughput and high data rates, and also offers high-speed connectivity at the user end. However, this massive upgrade has increased to bandwidth scarcity, [1] which further restricts the required advancements, while consuming limited spectrum $<3 \mathrm{GHz}$ [2].

To meet the $5 \mathrm{G}$ requests and facilitate higher capacity, greater data rate, extra connectivity, advanced reliability and minimum latency. The design approaches for antenna has higher necessity, in future $5 \mathrm{G}$ wireless communication network will mostly use the high frequency band [3]. The research works which has been performed by the authors on designing 5G antennas [4]. The 5G technology is expected to provide much wider than the previous one as frequency bands along with the wider spectral bandwidth per frequency channel. The $5 \mathrm{G}$ is also advanced in terms of high capacity to allow more devices connectivity at same time, lower battery consumption, better connectivity irrespective of the geographic region, lower cost of infrastructural development, higher reliability of the communications, highly increased peak bit rate, larger data volume per unit area. Available spectrum at the millimetre-waves (MMWs) is used in the future $5 \mathrm{G}$ demands of high capacity and throughput.

Micro strip patch antenna is necessary and practical component of communication systems. It is more suitable option for the microwave designers for simple design, low profile and a compact structure. The most disadvantage of the microstrip antenna is low return loss, less bandwidth and low gain [5]. Consistent with the microwave researches for the high performance 


\section{International Journal of Engineering Applied Sciences and Technology, 2020 \\ Vol. 5, Issue 1, ISSN No. 2455-2143, Pages 457-461 \\ Published Online May 2020 in IJEAST (http://www.ijeast.com)}

the microstrip patch antenna should be reduced [6]. The four techniques to feed the microstrip antennas are the microstrip line, coaxial probe, aperture coupling, and proximity coupling. For this challenge, several methods are proposed recently using geometry, slots on patch antenna, using dielectric substrates, Defected Ground Structure(DGS), Magneto-Dielectric Substrates and therefore the Electromagnetic band gap (EBG) [7].

DGSs can control the excitation and propagation of electromagnetic waves in the substrate of the antenna. In microstrip antennas, this technique has been used to improve the antenna performance in terms of increasing the bandwidth. The printed planar slot antennas have become very attractive for wireless systems thanks to their low profile, wide bandwidth, compact size, ease of fabrication, etc. When a slot antenna is fed by a microstrip line, it doesn't add weight and size to the system and is suitable for portable applications [8].

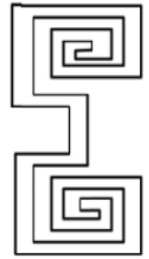

(a)

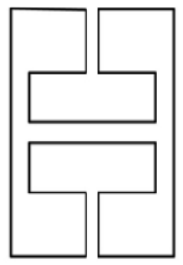

(d)

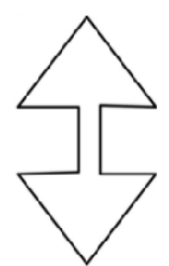

(b)

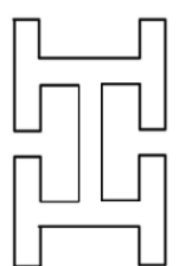

(c)

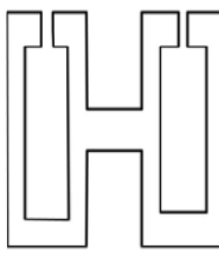

(e)

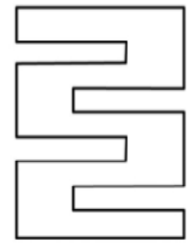

(f)
Fig1: Different shapes of Defeated Ground Structure (DGS)

These are the different shapes of Defeated Ground Structure(DGS), but in this proposed antenna full ground is reduced to $1 / 4$ th of ground. In this paper, defected ground structure (DGS) technique is used in the goal to miniaturize the proposed micro strip antenna. After the use of DGS method the antenna resonates at $4.6 \mathrm{GHz}$ for INSAT, WLAN and telecommunication applications.

\section{ANTENNA DESIGN}

The two types of antennas have designed. They are antenna without DGS and with DGS.

\section{A. Antenna without DGS}

To investigate potential of DGS structure is to shift the resonance frequency of microstrip antenna. The antenna without DGS structure it resonates at $5.5 \mathrm{GHz}$, the width $(\mathrm{W})$ and the length $(\mathrm{L})$ of the patch antenna can be designed by using the formulas given in below. The width of the Microstrip patch antenna is given by equation as:

$$
\begin{aligned}
& \mathrm{W}=\frac{c}{2 f \sqrt{0 \sqrt{\frac{(\varepsilon \mathrm{r}+1)}{2}}}}, \quad \mathrm{~L}=\frac{c}{2 f \sqrt{\varepsilon_{r}}}-2 \Delta L \\
& \varepsilon_{e}=\frac{\varepsilon_{r}+1}{2}+\frac{\varepsilon_{r}-1}{2}\left(1+\frac{12 h}{W}\right)^{-1 / 2}
\end{aligned}
$$

$\Delta \mathrm{L}$ equation is:

$$
\Delta L=h .(0.412) \frac{\left(\varepsilon_{e}+0.3\right)\left(\frac{W}{h}+0.264\right)}{\left(\varepsilon_{e}-0.258\right)\left(\frac{W}{h}+0.8\right)}
$$

In this design, FR-4 substrate is used because of low cost and easy fabrication. The substrate height is $1.6 \mathrm{~mm}$, the dielectric constant is 4.4 and the loss tangent is 0.025 . The total size of the proposed antenna is $33 \times 39 \mathrm{~mm} 2$, optimum values of the antenna are as follows $\mathrm{Wp} 1=6 \mathrm{~mm}, \mathrm{Wp} 2=6 \mathrm{~mm}$, $\mathrm{Lp} 1=3 \mathrm{~mm}, \mathrm{Lp} 2=3 \mathrm{~mm}, \mathrm{Lf} 1=5 \mathrm{~mm}, \mathrm{Lf} 2=10 \mathrm{~mm}, \mathrm{Wf} 1=$ $1 \mathrm{~mm}, \mathrm{Wf} 2=1.5 \mathrm{~mm}, \mathrm{~S} 1=3 \mathrm{~mm}, \mathrm{~S} 2=3 \mathrm{~mm}, \mathrm{~S} 3=3 \mathrm{~mm}, \mathrm{~S} 4$ $=3 \mathrm{~mm}$ and metallization thickness of $\mathrm{t}=1.6 \mathrm{~mm}$. The dimensions of the partial conducting ground plane are $\mathrm{Wg}=39 \mathrm{~mm}$ and $\mathrm{Lg}=33 \mathrm{~mm}$.

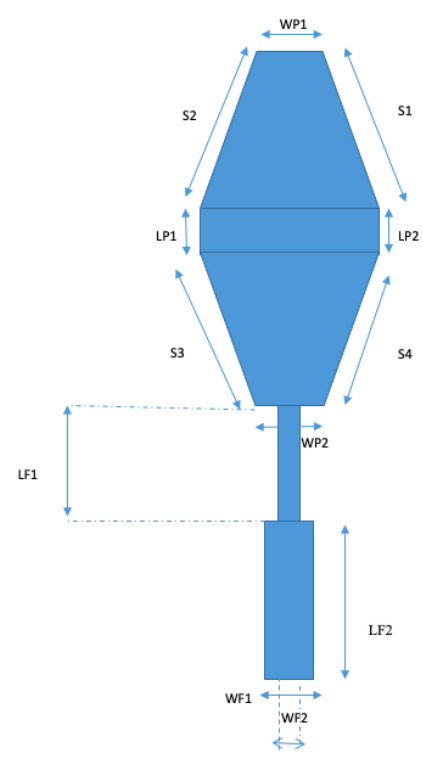

Fig2: Geometry of the proposed antenna

The simulated return loss obtained for this antenna by using ADS is shown in Fig.3.The return loss is $-32 \mathrm{db}$ at $5.5 \mathrm{GHz}$. 
International Journal of Engineering Applied Sciences and Technology, 2020

Vol. 5, Issue 1, ISSN No. 2455-2143, Pages 457-461

Published Online May 2020 in IJEAST (http://www.ijeast.com)

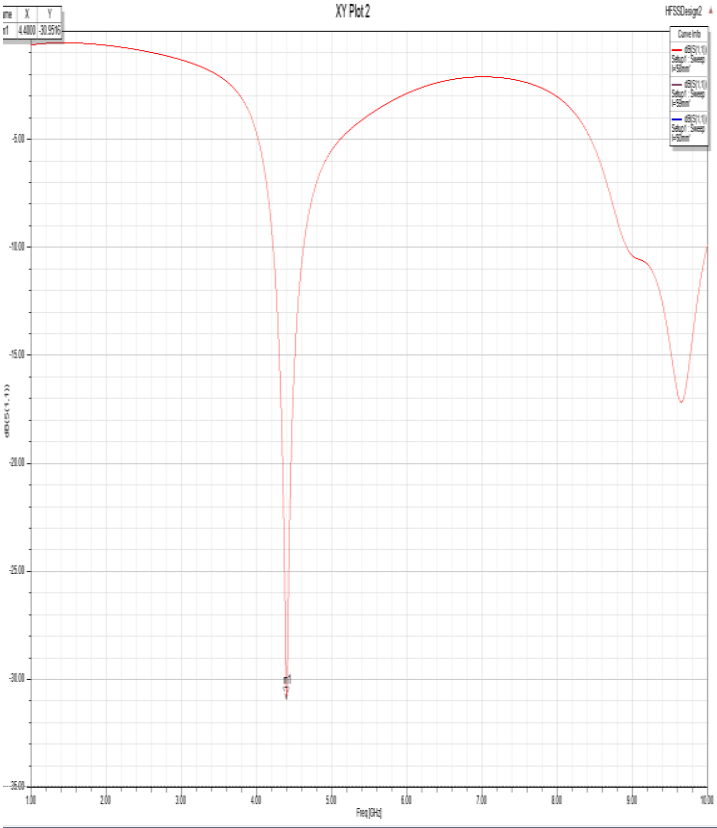

Fig3: Simulation of return loss for the antenna without DGS using ADS.

\section{B. Defected Ground Structures (DGS)}

Fig.4 shows the layout of the DGS structure located on the metallic ground plane, that is reduced to $1 / 4^{\text {th }}$ of ground. The resonant frequency can be shifted by varying the dimensions of the ground.

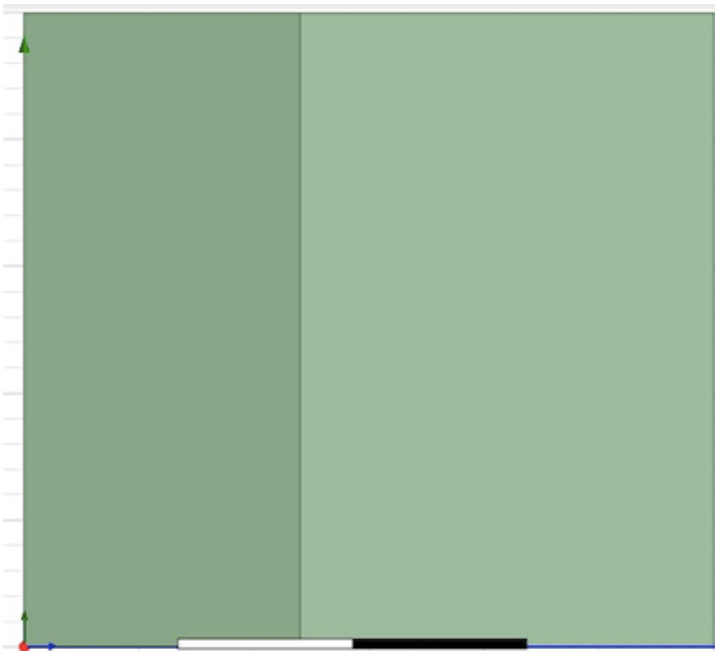

Fig4: Geometry for the proposed DGS.

\section{SIMULATION RESULTS OF THE ANTENNA WITH DGS}

The simulated reflection coefficient of the proposed antenna shows good matching at $4.6 \mathrm{GHz}$ with a bandwidth equal to $7.32 \mathrm{GHz}$, which is from 1.05 $\mathrm{GHz}$ to $8.37 \mathrm{GHz}$. With a return loss $-47.8 \mathrm{~dB}$. The result obtained for the reflection coefficient with DGS is shown in Fig. 6. We can see that the effect of the DGS shaped permit to shift the resonant frequency from $5.5 \mathrm{GHz}$ to $4.6 \mathrm{GHz}$.

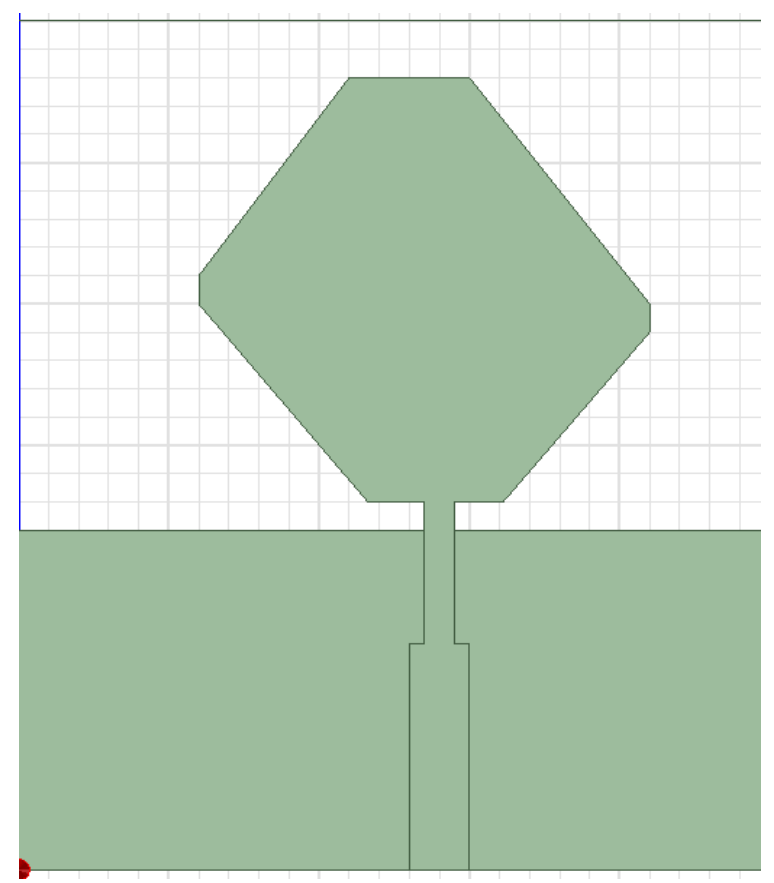

Fig5: Micro strip patch antenna with DGS.

\section{A. Return Loss and Bandwidth}

Return Loss:

In telecommunication return loss is the loss of signal power resulting from the reflection occur at a discontinuity in a transmission line. Return loss is said to both wave ratio and reflection. Increasing return coefficient loss corresponds to lower. The return loss is high whenever the match is good. In the referred paper the return loss is $-33 \mathrm{~dB}$ but in the proposed design the return loss is $-47 \mathrm{~dB}$.

\section{Bandwidth:}

Bandwidth is one of the most important parameter in the antenna design. Bandwidth describes the range of frequencies over which the antenna can properly radiate. In general, narrow bandwidth is used for more antennas operations and cannot be used for wide band operations. In proposed antenna the bandwidth is very high that is $7.2 \mathrm{GHz}$. 


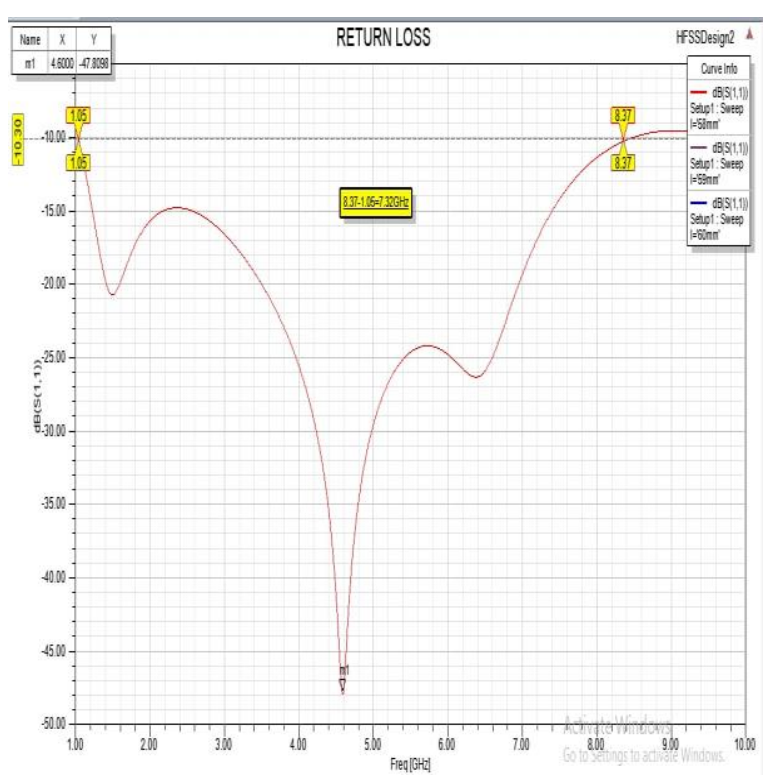

Fig6: Simulation of Return loss for the antenna with DGS at $4.6 \mathrm{GHz}$.

\section{B. Voltage Standing Wave Ratio (VSWR)}

VSWR is real and positive for an antenna. In the proposed design the VSWR is less while compared to the other references. By applying the DGS technique VSWR is $1.008 \mathrm{~dB}$ at resonant frequency of $4.6 \mathrm{GHz}$.

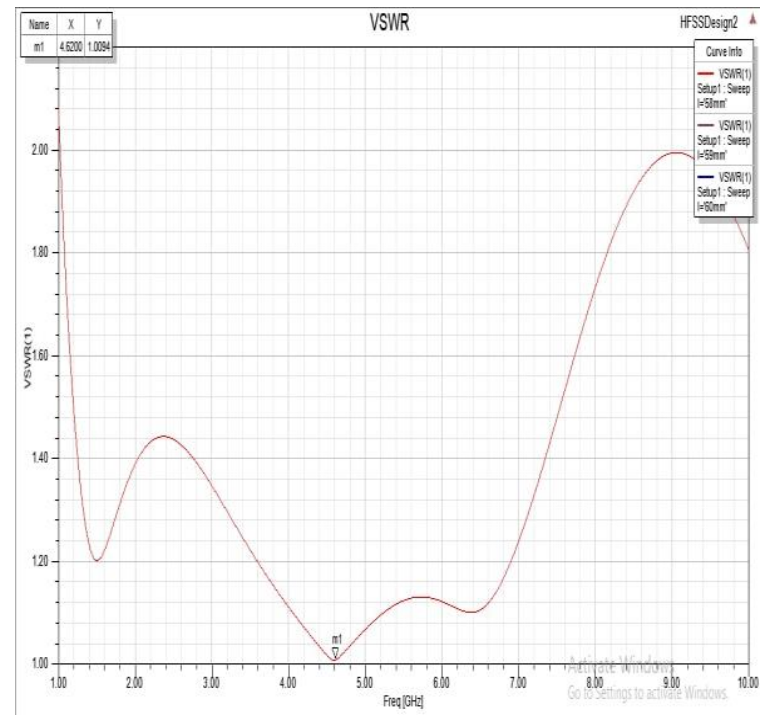

Fig7: Simulation of VSWR for the antenna with DGS at $4.6 \mathrm{GHz}$.

\section{Impedance Matching}

Impedance matching is also vital parameter in antenna design. Antenna impedance relates the voltage of present input. It is more useful within the high frequency section. Generally the cable will transform the impedance to the antenna it is very difficult to deliver power, unless the antenna is matched to the cable. During this design the impedance is matched at $50 \mathrm{ohms}$ so, it'll be more useful to deliver the facility.

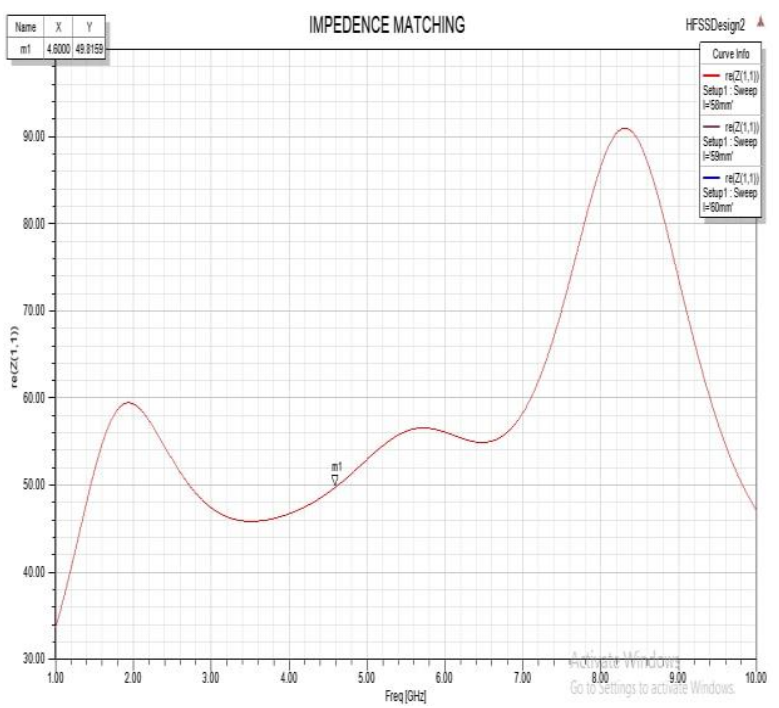

Fig8: Simulation of Impedance matching for the antenna with DGS at $4.6 \mathrm{GHz}$.

\section{CONCLUSION}

In this paper we have developed a new study concerning the microstrip patch antenna by using defected ground structure DGS resonating at 4.6 $\mathrm{GHz}$. The goal of the work is to shift the resonance frequency from $5.5 \mathrm{GHz}$ to $4.6 \mathrm{GHz}$. A microstrip patch antenna has been developed, analysed and valid for INSAT, WLAN and telecommunication applications.

\section{REFERENCES}

[1] Rappaport, T.S., Sun, S., Mayzus, R., et al.: 'Millimeter wave mobile communications for $5 \mathrm{G}$ cellular: 2013. It will work!', IEEE Access, 1, pp. 335-349.

[2] Jilani, S. F., \& Alomainy, A. Millimetre-wave T-shaped MIMO antenna with defected ground structures for 5G cellular networks 2018. IET Microwaves, Antennas \& Propagation, 12(5), 672677.

[3]Wang, C.-X., Haider, F., Gao, X., You, X.-H., Yang, Y., Yuan, D., ... Hepsaydir, E. Cellular architecture and key technologies for 5G wireless communication networks. IEEE Communications Magazine, 52(2), 122-130. 2014.

[4] Zhinong Ying. Antennas in Cellular Phones for Mobile Communications, July 2012. Proceedings of the IEEE, 100(7). 
[5] Er-rebyiy, R., Zbitou, J., Tajmouati, A., Latrach, M., Errkik, A., \& El Abdellaoui, L. A new design of a miniature microstrip patch antenna using Defected Ground Structure DGS. 2017 International Conference on Wireless Technologies, Embedded and Intelligent Systems

[6] Mr. Kartik Ramesh Patel, Dr. Ramesh Kulkarni "Ultra-Wideband (UWB) Wireless System 2014. "(IJAIEM) Special Issue for International Technological Conference.

[7] Roy, A., Choudhary, P. K., Anand, S., Sarkar, P. P., \& Bhunia, S. "A novel approach on miniaturization of microstrip patch antenna with loaded strips," Jan 2014 Electronics, Communication and Instrumentation (ICECI), International Conference, pp. 1-4,16-17 .

[8] Claudius Locker, Thomas Vaupel, Thomas F.Eibert,"Radiation Efficient Unidirectional LowProfile Slot Antenna Elements For X-Band Applications", Volume: 53, Aug. 2005.

[9] N. Bayatmaku, P. Lotfi, M. Azarmanesh, and S. Soltani, "Design of simple multi-band patch antenna for mobile communication applications using new E-shape fractal," 2011. IEEE Antennas Wireless Propag. Lett., vol. 99, p. 1.

[10] Shekhar, C.; Bhadauria, A.; Radhakrishna, M." Application of 2D defected ground structures in microstrip lines," Jan. 2013 IEEE CONECCT, pp. 1 - 4.

[11] Rezaul Azim and Mohammad Tariqul Islam : chapter 7 "Printed wide slot Ultra-Wideband Antenna" INTECH 2013.

[12] Abraham Ortega, Leonardo R.A.X. de Menezes, A.J. Martins Soares and Humberto Abdalla Jr "Design of Low-Pass Microstrip Filters Based on Defected Ground Structure,", 21-24 Nov. 2008. 2011 IEEE Explore pp. 69 - 74.

[13] Haiwen Liu, Xiaowei Sun and Zhengfan Li "A new parameter extraction method for DGS and its application to the low-pass filter," IEEE Explore, June 2004, Vol. 27, pp. 119-123 